\title{
Stone clearance times with mini-percutaneous nephrolithotomy: Comparison of a 1.5 mm ballistic/ultrasonic mini-probe vs. laser
}

Brennan Timm ${ }^{1}$; Matthew Farag ${ }^{1}$; Niall F. Davis ${ }^{2}$; David Webb ${ }^{1}$; David Angus ${ }^{1}$; Andrew Troy $^{1}$; Damien Bolton ${ }^{1}$; Gregory Jack ${ }^{1}$

${ }^{1}$ Department of Urology, Austin Health, University of Melbourne, Melbourne, Australia; ${ }^{2}$ Department of Urology, Beaumont and Connolly Hospitals, Dublin, Ireland

Cite as: Can Urol Assoc J 2020 July 17; Epub ahead of print. http://dx.doi.org/10.5489/cuaj.6513

Published online July 17, 2020

$* * *$

Abstract

Introduction: A limitation of mini-percutaneous nephrolithotomy (mPCNL) is the narrow working channel of mini-nephroscopes, typically restricting instrumentation to $5 \mathrm{~F}$ or smaller. We evaluated the efficacy of the $1.5 \mathrm{~mm}$ Swiss Lithoclast ${ }^{\circledR}$ Trilogy (Trilogy) rigid probe and compared the results to consecutive cases performed with a $30 \mathrm{~W}$ Holmium:YAG (Ho:YAG) laser.

Methods: A retrospective review of 30 consecutive $\mathrm{mPCNL}$ cases using the Trilogy and 30 W Holmium laser was performed. A 12-French (F) MIPS nephroscope with a $16.5 \mathrm{~F}$ access sheath and 6.7 F working channel was used for all mPCNL cases. The Trilogy was used with a disposable $1.5 \mathrm{~mm}$ x $440 \mathrm{~mm}$ probe with dual ultrasonic and ballistic energy. The Ho:YAG laser was used with a 550 micron fibre and a maximum of $30 \mathrm{~W}$. Stone clearance time (SCT) was defined by the total time interval between activation of the lithotripter until insertion of the nephrostomy tube and measured in $\mathrm{mm}^{2} /$ minutes. SCT included time for fragment retrieval, equipment adjustments, and rigid and flexible nephroscopy during and after lithotripsy.

Results: Eleven cases using a $1.5 \mathrm{~mm}$ Trilogy probe and 16 cases using a Ho:YAG laser met final inclusion criteria. Three cases using the Trilogy were excluded from final analysis due to conversion to alternative energy sources - two of those were upsized to standard PCNL and one was converted to laser. Mean stone diameter and density in the final Trilogy cohort was $26.7 \mathrm{~mm}$ and 1193 Hounsfield units (HU). Mean diameter and density in the laser cohort was $25.2 \mathrm{~mm}$ and $1049 \mathrm{HU}$. The mean stone area clearance time for Trilogy was $4.7 \pm 1.8$ $\mathrm{mm}^{2} /$ minute vs. $3.4 \pm 0.7 \mathrm{~mm}^{2} /$ minute with Ho:YAG laser $(\mathrm{p}=0.21)$. For hard stones, defined as density $>1000 \mathrm{HU}$, the Trilogy averaged $3.7 \pm 1.6 \mathrm{~mm}^{2} /$ minutes, while the laser averaged $3.1 \pm 1.3 \mathrm{~mm}^{2} /$ minutes $(\mathrm{p}=0.786$ ). For soft stones, defined as $<1000 \mathrm{HU}$, the Trilogy averaged $8.9 \pm 1.0 \mathrm{~mm}^{2} /$ minutes compared to the Ho:YAG, which averaged $3.6 \pm 1.8 \mathrm{~mm}^{2} /$ minutes $(\mathrm{p}=0.019)$. No device0related complications occurred in either cohort. 
Conclusions: The $1.5 \mathrm{~mm}$ mPCNL Trilogy probe was comparable to $30 \mathrm{~W}$ Ho:YAG laser for clearing hard stones. The Trilogy performed better than laser on soft stones with a HU density $<1000 \mathrm{HU}$.

\section{Introduction}

Mini-percutaneous nephrolithotomy (mPCNL) was introduced in the 1990s in an effort to decrease morbidity associated with standard (24-30F) percutaneous nephrolithotomy (sPCNL) tracts. ${ }^{1}$ The EAU guidelines on urolithiasis recommend that mPCNL is safe and effective and may be used as an alternative to SPCNL, although further prospective research is required. ${ }^{2}$ Studies have shown reduced blood loss and shorter hospital length of stay with mPCNL compared to $\mathrm{SPCNL}^{3,4}$, although $\mathrm{mPCNL}$ operative times may be protracted and clearance rates inferior when compared with SPCNL, particularly with larger and harder stones. ${ }^{5} \mathrm{mPCNL}$ has been compared against flexible ureteropyloscopy (FURS) with lower pole stones, and randomized trials and meta-analysis have shown improved stone free rates (SFR) and comparable morbidity rates with mPCNL. ${ }^{6-8}$

A limitation of mPCNL is the small working lumen of mini-nephroscopes which do not allow for large kinetic lithotripter probes to pass. ${ }^{5}$ Pulsed lasers, such as Holmium:YAG (Ho:YAG), are popular energy sources for stone disintegration at mPCNL. Laser fibre diameters of $200-1000$ microns (um), or 1-5F with laser sheath, are easily accommodated and allow ample irrigation through the small working lumen of mini-nephroscopes. ${ }^{9}$ The limitations of lasers in $\mathrm{mPCNL}$ include the slower fragmentation times for large stones compared to kinetic and ultrasonic lithotripters. ${ }^{10}$

Kinetic and ultrasonic lithotripters are able to fragment stones faster than laser but require large rigid probes to transmit their energy from the handpiece to the stone. Commercially available kinetic/ultrasonic lithotripters such as the Olympus Cyberwand ${ }^{\mathrm{TM}}$ (Olympus, Tokyo, Japan), the Olympus ShockPulse-SETM (Olympus, Tokyo, Japan), and Swiss Lithoclast ${ }^{\circledR}$ Master/select (Electro Medical Systems S.A., Switzerland) report stone area clearance times (SCTs) of $24-76 \mathrm{~mm}^{2} /$ minute $^{11,12}$ during sPCNL, although significant variability exists between studies. Initial reviews of the Swiss Lithoclast ${ }^{\circledR}$ Trilogy (Electro Medical Systems S.A., Switzerland) reported SCT of $68-230 \mathrm{~mm}^{2} /$ minute using $3.4 \mathrm{~mm}$ probes. ${ }^{13,14}$

Miniaturization of pneumatic and ultrasonic lithotripter probes to $<5 \mathrm{~F}$ to exploit the efficiency of kinetic and ultrasonic lithotripters in $\mathrm{mPCNL}$ has been eagerly anticipated. The ability to deliver ballistic impact, ultrasonic vibration and suction capabilities through a $<5 \mathrm{~F}$ lithotripter probe could potentially expand the role of $\mathrm{mPCNL}$ towards even larger stones. Invitro studies have reported efficient outcomes. ${ }^{(15)}$

The goal of this study was to objectively evaluate a $1.5 \mathrm{~mm}$ combined pneumatic/ultrasonic lithotripter probe during mPCNL. We benchmarked the mini-lithotripter probe against our hospital's previous energy source, a 30W Ho:YAG laser, in order to provide reference. 


\section{Methods}

Data was collated from a prospective dataset of operative times and outcomes of consecutive mPCNL cases at a tertiary referral hospital for renal stone management. Pre- and postoperative stone volume was assessed by computed tomography (CT) measurement of maximal 1, 2 and 3-axis dimensions. In cases with multiple stones, volumes were added together to report total stone volume. Ethics were approved through the Austin Health Office for Research against the principles of the National Statement on Ethical Conduct in Research (2007, updated 2018) HREC (Audit/20/Austin/06)

\section{Study cohort}

All patients undergoing mPCNL with 30W Ho:YAG laser or Trilogy $1.5 \mathrm{~mm} \times 440 \mathrm{~mm}$ miniPCNL probe at our institution from June 2019 until January 2019 were included. Patients who required upsizing to SPCNL, conversion to alternative enery sources, nephroscopy without lithotripsy, or combined retrograde intra-renal surgery were excluded from final analyses.

\section{Mini-PCNL}

Procedures were supervised by 5 PCNL surgeons at a teaching hospital performing 60 $\mathrm{mPCNL}$ per year. All surgeons had $>5$ years experience with $\mathrm{mPCNL}$, Holmium laser, and Swiss lithoclast. All procedures were performed under general anesthetic in a prone position. Only unilateral procedures were performed. A Karl Storz ${ }^{\mathrm{TM}}$ 12F MIPS Nephroscope (Karl Storz SE \& Co, Tuttlingen, Germany) with a $16.5 \mathrm{~F}$ outer sheath, and a $6.7 \mathrm{~F}$ single flow working channel able to accommodate instruments up to $5 \mathrm{~F}$ according to the manufacturer's specifications was used. All cases were drained with a 10F nephrostomy at case conclusion.

\section{Lithotripsy}

The Swiss Lithoclast ${ }^{\circledR}$ Trilogy (Electro Medical Systems S.A., Switzerland) had 4 adjustable energy levels: impact, hertz, ultrasound, and suction, and all were adjusted at the surgeon's discretion to optimise treatment efficacy for the individual calculus. Only the $1.5 \mathrm{~mm} \times 440$ disposable probe (Electro Medical Systems S.A., Switzerland) was evaluated for this study.

\section{The Ho}

YAG laser (Odyssey 30, Convergent laser technologies, California, USA) had a maximum power of $30 \mathrm{~W}$, energy range of $0.4-3.0 \mathrm{~J}$, and frequency range of $5-20 \mathrm{~Hz}$. Energy settings were determined at surgeon discretion based on optimising stone fragmentation. A 550um fibre was used with all cases.

\section{Endpoints}

Procedure details, operative times, and lithotripsy details were abstracted from the surgical dataset and analysed. Stone clearance time was defined as the time interval from activation of the lithotripter until insertion of the nephrostomy tube at procedure conclusion. Stone clearance time included time spent on stone fragment retrieval with forceps, nitinol baskets, venturi effect, equipment adjustments, and rigid and flexible nephroscopy after lithotripsy until insertion of nephrostomy. Time required for percutaneous access, and percutaneous 
nephrostomy placement were excluded. SFR in both groups was determined by CT or US within 12-weeks of mPCNL.

\section{Results}

Fourteen patients using a $1.5 \mathrm{~mm}$ Trilogy probe, and 16 cases using a Ho:YAG laser were analysed. Three cases in the Trilogy cohort were excluded from final analysis due to caseconversion to another technology. Two of these cases were upsized to SPCNL with the Trilogy $3.2 \mathrm{~mm}$ probe and one case remained as $\mathrm{mPCNL}$ but converted to the $30 \mathrm{~W}$ Ho:YAG with a 550um fibre. All three cases were excluded from final analysis below.

27 patients met final inclusion, 18 males and 9 females. Median age was 59.5 years in the Trilogy group and 58.7 years in the Holmium group. In the Trilogy group the mean stone dimension, and stone area (2-axis CT measurement) were $26.7 \mathrm{~mm}$ and $425.6 \mathrm{~mm}^{2}$ respectively. In the Holmium laser group, measurements were $25.2 \mathrm{~mm}$ and $341.1 \mathrm{~mm}^{2}$ respectively. $54.5 \%$ of Trilogy patients had $\geq$ two stones in comparison to $43.8 \%$ in the laser group $(p=0.578)$. Mean stone density in the Trilogy group was $1,193.4 \pm 283.3$ Hounsfield units (HU), versus $1,049.3 \pm 206.0 \mathrm{HU}$ in the laser group $(\mathrm{p}=0.217)$.

Ho: YAG laser settings varied intra-operatively according to case flow and surgeon preference, with a median setting of $1.5 \mathrm{~J}$ (range $0.6-2.0 \mathrm{~J}$ ) and $12 \mathrm{~Hz}$ (range 8-20). Median energy settings for the Trilogy were 90\% impact, 90\% ultrasound, 90\% suction, 5 hertz respectively.

The mean stone area clearance time was $4.7 \pm 1.8 \mathrm{~mm}^{2} / \mathrm{min}$ in the Trilogy group and $3.4 \pm 0.7 \mathrm{~mm}^{2} / \mathrm{min}$ in the laser group $(\mathrm{p}=0.218)$. When considering stone volumes, the mean clearance times were $70.4 \pm 35 \mathrm{~mm}^{3 /} \mathrm{min}$ and $37.6 \pm 8 \mathrm{~mm}^{3 /} \mathrm{min}$ in the Trilogy and laser groups respectively. The $1.5 \mathrm{~mm}$ trilogy probe performed better on soft stones $(<1000 \mathrm{HU})$, with an average stone area clearance time of $8.9 \pm 1.0 \mathrm{~mm}^{2} / \mathrm{min}$ for soft stones compared to the Ho:YAG group which averaged $3.6 \pm 1.8 \mathrm{~mm}^{2} / \mathrm{min}$ for soft stones $(p=0.019)$. For hard stones $(>1000 \mathrm{HU})$, Trilogy averaged $3.7 \pm 1.6 \mathrm{~mm}^{2} / \mathrm{min}$, similar to the laser which averaged $3.1 \pm 1.3 \mathrm{~mm}^{2} / \mathrm{min}(\mathrm{p}=0.786)$. The SFR, defined as no residual fragments of any size, was $55.5 \%$ and $62.5 \%$ in the Trilogy and Ho:YAG groups respectively $(\mathrm{p}=0.257)$. (Table 1 ) (Table 2). $100 \%$ of the cases in both cohorts had stone volume reductions of $95 \%$ or more. No device related complications occurred in either group.

\section{Discussion}

This study compares the in-vivo stone clearance times of the Swiss Lithoclast ${ }^{\circledR}$ Trilogy using a mini $1.5 \mathrm{~mm}$ ballistic/ultrasonic probe against a 30W Ho:YAG laser using a 550um fibre during mPCNL.

Technological advancements in mPCNL have allowed surgeons to take on larger and more complex renal stones with reduced blood loss and length of hospital stay. ${ }^{3,4,16,17}$ The use of Ho:YAG laser is well documented in mPCNL due to safety, efficacy and the small caliber of laser fiber which is easily accommodated through the small working channel of miniaturized nephroscopes. ${ }^{9,}{ }^{18}$ Disadvantages to the use of Ho:YAG laser include increased anesthesia time associated with fragmenting and retrieving stone fragments, 
purchase/maintenance costs of the laser and costs of extended operative duration, and inadvertent laser exposure to patient or operating staff. ${ }^{10,19}$

Kinetic lithotripters utilizing ultrasonic and ballistic energy offer high efficiency and low-cost stone management. ${ }^{20,21}$ The stone clearance times generated from modern dual energy kinetic lithotripters are faster than previous equipment versions. Using the Swiss Lithoclast ${ }^{\circledR}$ Trilogy, Sabnis et al were able to achieve a stone volume clearance time of $590 \mathrm{~mm}^{3} / \mathrm{min}$ with a $3.4 \mathrm{~mm}$ rigid probe during $\mathrm{sPCNL}$ and $370 \mathrm{~mm}^{3 /} \mathrm{min}$ using a $1.9 \mathrm{~mm}$ probe during mPCNL. ${ }^{14}$ Our study examines the smaller $1.5 \mathrm{~mm}$ lithotripter probe, and benchmarks it against a standard $30 \mathrm{~W}$ laser for comparison. In comparison to the studies above with larger probes, we calculated a volume clearance time of $70.4 \mathrm{~mm}^{3} / \mathrm{min}$ using the $1.5 \mathrm{~mm}$ probe, and $37.6 \mathrm{~mm}^{3} / \mathrm{min}$ using a $30 \mathrm{~W}$ Ho:YAG laser.

We hypothesize that our slower clearance times are due to the smaller $1.5 \mathrm{~mm}$ diameter of the probe we employed, as well as our broad definition of clearance time. We defined clearance time as total time from commencement of lithotripsy until placement of a nephrostomy tube. We chose this measure, as opposed to time the laser or lithotripter was actively deploying energy, in order to incorporate nephroscopy time to localise fragments, fragment extraction time and device setting manipulations.

When comparing the Trilogy SCTs with the Ho:YAG laser, there was a time advantage in using the Trilogy on soft stones $<1000 \mathrm{HU}$ (Figure 1) where stone area clearance time was $8.9 \pm 1.0 \mathrm{~mm}^{2} / \mathrm{min}$ versus $3.6 \pm 1.8 \mathrm{~mm} \mathrm{~mm} / \mathrm{min}$ for the laser $(p=0.019)$. This advantage was not apparent in the hard-stone group where rates were $3.7 \pm 1.6 \mathrm{~mm}^{2} / \mathrm{min}$ and $3.1 \pm 1.3 \mathrm{~mm}^{2} / \mathrm{min}$ respectively for stones $>1000 \mathrm{HU}(\mathrm{p}=0.786)$.

The stones treated in the Trilogy group were had a trend to be larger stones than those in the Ho:YAG group, although not statistically significant $(26.7 \mathrm{~mm}$ versus $25.3 \mathrm{~mm}$ $\mathrm{p}=0.696 ; 488.1 \mathrm{~mm}^{2}$ versus $341.1 \mathrm{~mm}^{2} \mathrm{p}=0.231$; and $5,936.5 \mathrm{~mm}^{3}$ versus $3724.0 \mathrm{~mm}^{3} \mathrm{p}=0.076$ respectively). In the trilogy cohort there were 3 cases where the stone area was $>600 \mathrm{~mm}^{2}$ versus one case in the laser cohort. We believe due to this larger stone size, the lithotripsy duration was higher overall in the Trilogy group compared with the laser despite stone clearance times being better.

These larger stone cases may have been better served by treatment with sPCNL and a larger lithotripter probe. We explain this in part due to the surgeon attempting to trial the full capabilities of the of the mPCNL capable $1.5 \mathrm{~mm}$ Trilogy probe. Indeed, two cases with larger stones were initially attempted with $\mathrm{mPCNL}$ with the $1.5 \mathrm{~mm}$ Trilogy probe but were upsized to $\mathrm{SPCNL}$ with a $3.4 \mathrm{~mm}$ probe and excluded from final analysis. In one case the $1.5 \mathrm{~mm}$ Trilogy probe was unable to fragment a $1620 \mathrm{HU}$ stone and conversion to Ho:YAG laser was undertaken with good result. This case was only the second case where the Trilogy had been trialed by the surgeon and conversion may be attributed to the learning curve of a new device. Subsequent cases with the Trilogy on stones of high density were slightly more effective.

The Trilogy was showed a similar SFR to the laser in this study. We believe our overall low SFR in both cohorts were due to the sizes of the larger stones treated, as well as our definition of stone free, which we defined as no visible fragments of any size on post-op 
$\mathrm{CT}$ or ultrasound. Other authors have defined SFR as no fragments on imaging $>3 \mathrm{~mm}$, or no visible fragments at the conclusion of nephroscopy. ${ }^{8}$

Median hospital length of stay encountered in both groups was three days. One complication occurred in each of the cohorts. A Clavien grade IIIa complication, an arteriovenous fistula into the collecting system, from an inferior pole puncture site presenting on day 20 was treated by transfusion and selective embolization by interventional radiologist in the Trilogy cohort. We believe this late complication to be due to puncture and renal access, rather than associated with the device. A Clavien grade II complication of perinephric haematoma with haemoglobin drop requiring transfusion and urosepsis requiring antibiotics occurred in the laser cohort. It is possible that the infective complication experienced in the laser cohort could be related to increased intra-renal pressure due to lack of negative pressure suction when using a laser as compared with the Trilogy. All cases however were performed with adequate drainage through a $16.5 \mathrm{~F}$ access sheath, and therefore intra-renal pressures were likely relatively equal in both cohorts.

In conclusion, the $1.5 \mathrm{~mm}$ Trilogy probe is comparable to the $30 \mathrm{~W}$ Ho:YAG laser in our series. Improved clearance times for soft stones were found with the Trilogy compared to the 30W Ho:YAG laser.

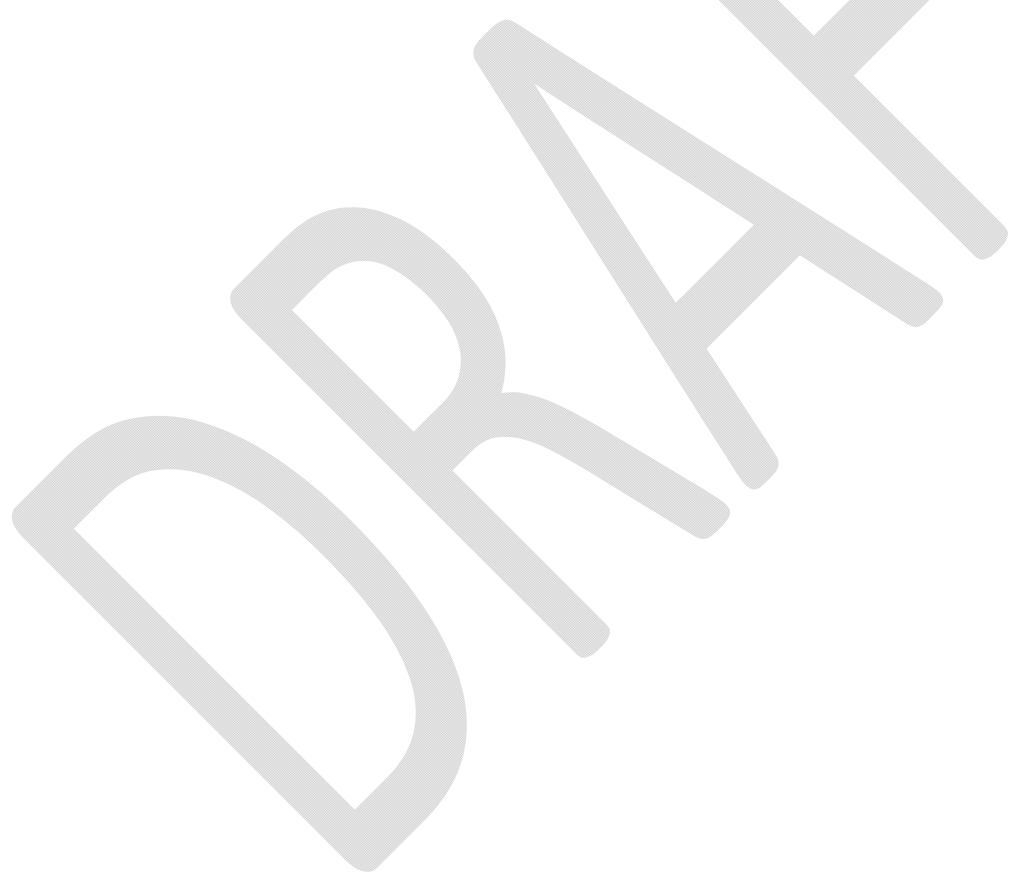




\section{References}

1. Monga M, Oglevie S. Minipercutaneous nephrolithotomy. J Endourol 2000;14(5):419-21.

2. C. Türk AS, A. Neisius, A. Petřík, et al. EAU guidelines on urolithiasis 2019 [Available from: https://uroweb.org/guideline/urolithiasis/.Accessed February 6,2020 .

3. Hennessey DB, Kinnear NK, Troy A, et al. Mini PCNL for renal calculi: does size matter? BJU Int 2017;119(S5):39-46.

4. Mishra S, Sharma R, Garg C, et al. Prospective comparative study of miniperc and standard PNL for treatment of 1 to $2 \mathrm{~cm}$ size renal stone. BJU Int 2011;108(6):8969; discussion 9-900.

5. Ruhayel Y, Tepeler A, Dabestani S, et al. Tract Sizes in Miniaturized Percutaneous Nephrolithotomy: A Systematic Review from the European Association of Urology Urolithiasis Guidelines Panel. Eur Urol 2017;72(2):220-35.

6. Gao XS, Liao BH, Chen YT, et al. Different Tract Sizes of Miniaturized Percutaneous Nephrolithotomy Versus Retrograde Intrarenal Surgery: A Systematic Review and Meta-Analysis. J Endourol 2017;31(11):1101-10.

7. Davis NF, Quinlan MR, Poyet C, et al. Miniaturised percutaneous nephrolithotomy versus flexible ureteropyeloscopy: a systematic review and meta-analysis comparing clinical efficacy and safety profile. World J Urol 2018;36(7):1127-38.

8. Zeng G, Zhang T, Agrawal M, et al. Super-mini percutaneous nephrolithotomy (SMP) vs retrograde intrarenal surgery for the treatment of 1-2 cm lower-pole renal calculi: an international multicentre randomised controlled trial. BJU Int 2018;122(6):1034-40.

9. Ganesamoni R, Sabnis RB, Mishra S, et al. Prospective randomized controlled trial comparing laser lithotripsy with pneumatic lithotripsy in miniperc for renal calculi. $J$ Endourol 2013;27(12):1444-9.

10. Geraghty RM, Jones P, Herrmann TRW, et al. Ureteroscopy is more cost effective than shock wave lithotripsy for stone treatment: systematic review and metaanalysis. World j urol 2018;36(11):1783-93.

11. York NE, Borofsky MS, Chew BH, et al. Randomized Controlled Trial Comparing Three Different Modalities of Lithotrites for Intracorporeal Lithotripsy in Percutaneous Nephrolithotomy. J Endourol 2017;31(11):1145-51.

12. Krambeck AE, Miller NL, Humphreys MR, et al. Randomized controlled, multicentre clinical trial comparing a dual-probe ultrasonic lithotrite with a singleprobe lithotrite for percutaneous nephrolithotomy. BJU Int 2011;107(5):824-8.

13. Nottingham CU, Large T, Cobb K, et al. Initial Clinical Experience with Swiss LithoClast Trilogy During Percutaneous Nephrolithotomy. J Endourol 2019.

14. Sabnis RB, Balaji SS, Sonawane PL, et al. EMS Lithoclast Trilogy ${ }^{\mathrm{TM}}$ : an effective single-probe dual-energy lithotripter for mini and standard PCNL. World J Urol 2019.

15. Carlos EC, Wollin DA, Winship BB, et al. In Vitro Comparison of a Novel Single Probe Dual-Energy Lithotripter to Current Devices. J Endourol 2018;32(6):534-40.

16. $\mathrm{Gu} \mathrm{XJ}, \mathrm{Lu} J \mathrm{~L}, \mathrm{Xu} \mathrm{Y}$. Treatment of large impacted proximal ureteral stones: randomized comparison of minimally invasive percutaneous antegrade ureterolithotripsy versus retrograde ureterolithotripsy. World J Urol 2013;31(6):1605-10. 
17. Kumar A, Vasudeva P, Nanda B, et al. A Prospective Randomized Comparison Between Laparoscopic Ureterolithotomy and Semirigid Ureteroscopy for Upper Ureteral Stones >2 cm: A Single-Center Experience. J Endourol 2015;29(11):124852.

18. Kronenberg P, Traxer O. Update on lasers in urology 2014: current assessment on holmium:yttrium-aluminum-garnet (Ho:YAG) laser lithotripter settings and laser fibers. World J Urol 2015;33(4):463-9.

19. Althunayan AM, Elkoushy MA, Elhilali MM, et al. Adverse events resulting from lasers used in urology. $J$ Endourol 2014;28(2):256-60.

20. Erhard MJ, Bagley DH. Urologic applications of the holmium laser: preliminary experience. J Endourol 1995;9(5):383-6.

21. Jeon SS, Hyun J-H, Lee K-S. A comparison of holmium:YAG laser with Lithoclast lithotripsy in ureteral calculi fragmentation. International Journal of Urology 2005;12(6):544-7.

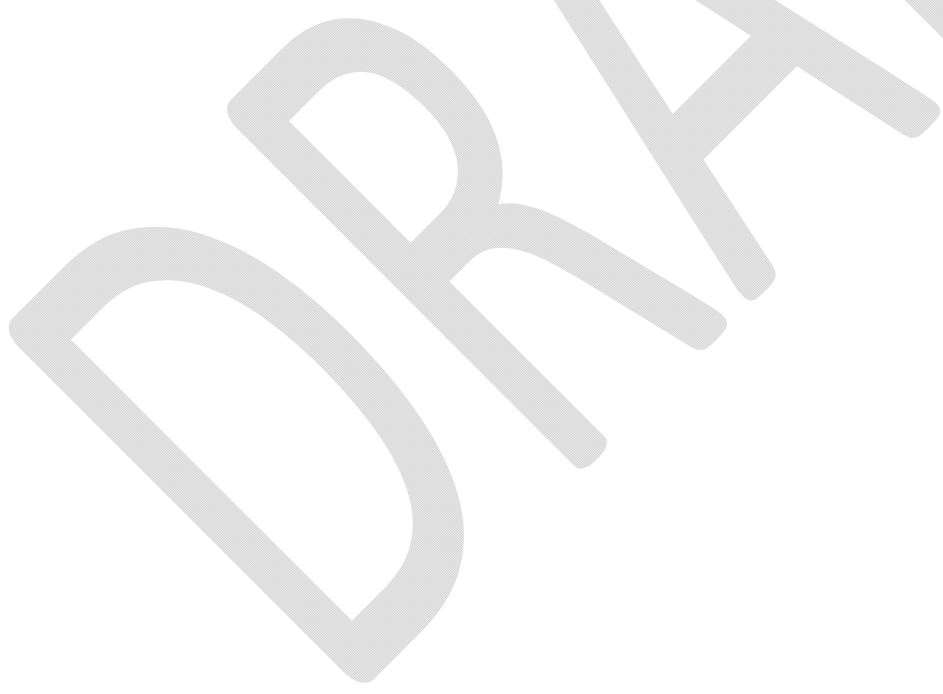




\section{Figures and Tables}

Fig 1. Clearance times comparing Trilogy $1.5 \mathrm{~mm}$ x $440 \mathrm{~mm}$ mini-PCNL probe and $30 \mathrm{~W}$ Ho:YAG laser on soft $(<1000 \mathrm{HU})$ and hard $(>1000 \mathrm{HU})$ intrarenal stones. PCNL: percutaneous nephrolithotomy.

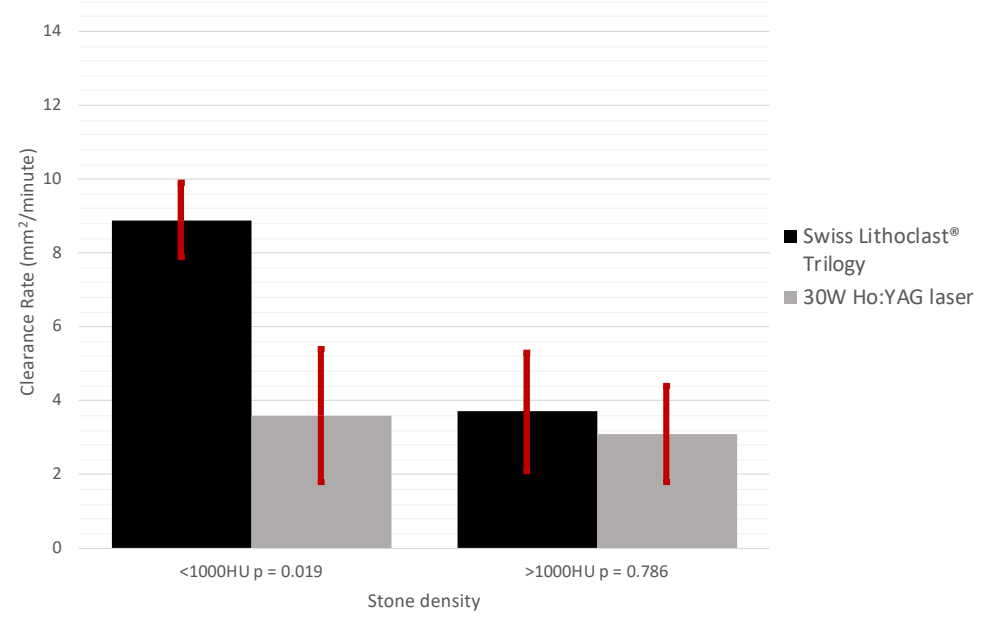

\begin{tabular}{|c|c|c|c|}
\hline & $\begin{array}{c}\text { Swiss Lithoclast }^{\circledR} \\
\text { Trilogy } 1.5 \text { mm probe }\end{array}$ & $\begin{array}{l}30 \text { W Ho: YAG laser } \\
\text { with } 550 \text { um fibre }\end{array}$ & $\mathbf{p}$ \\
\hline \multicolumn{4}{|c|}{ Patient demographics } \\
\hline Male: female & $9: 2$ & $9: 7$ & 0.856 \\
\hline PCNL left: right & $7: 4$ & $7: 9$ & 0.588 \\
\hline Median age (years) & 59.5 & 58.7 & 0.437 \\
\hline $\begin{array}{l}\text { Cases with } 2 \text { or more } \\
\text { stone on } \mathrm{CT}\end{array}$ & $54.50 \%$ & $43.80 \%$ & 0.578 \\
\hline 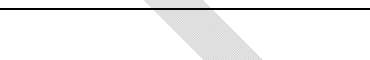 & Y & & \\
\hline $\begin{array}{l}\text { Stone } \\
\text { characteristics }\end{array}$ & $(\overline{\mathrm{x}} \pm \sigma)$ & $(\overline{\mathrm{x}} \pm \sigma)$ & \\
\hline Stone density, HU & $1193.4 \pm 283.3$ & $1049.3 \pm 206.0$ & 0.217 \\
\hline Stone dimension, $\mathrm{mm}$ & $26.7 \pm 4.0$ & $25.3 \pm 5.1$ & 0.348 \\
\hline Stone area, $\mathrm{mm}^{2}$ & $425.6 \pm 143.4$ & $341.1 \pm 101.6$ & 0.157 \\
\hline Stone volume, $\mathrm{mm}^{3}$ & $5936.5 \pm 2814.1$ & $3724.0 \pm 1318.3$ & 0.076 \\
\hline
\end{tabular}

CT: computed tomography; PCNL: percutaneous nephrolithotomy. 
Stone clearance times during mPCNL with Trilogy and laser

\begin{tabular}{|c|c|c|c|}
\hline & $\begin{array}{c}\text { Swiss Lithoclast }^{\circledR} \\
\text { Trilogy } 1.5 \mathrm{~mm} \\
\text { probe }\end{array}$ & $\begin{array}{c}30 \text { W Ho:YAG } \\
\text { laser with } 550 \\
\text { um fibre }\end{array}$ & $\mathbf{p}$ \\
\hline Intraoperative & $(\overline{\mathrm{x}} \pm \sigma)$ & $(\overline{\mathrm{x}} \pm \sigma)$ & \\
\hline $\begin{array}{l}\text { Lithotripsy duration } \\
\text { (minutes) }\end{array}$ & $90.9 \pm 28.1$ & $80.2 \pm 16.7$ & 0.259 \\
\hline $\begin{array}{l}\text { Stones }<1000 \mathrm{HU} \\
\text { (minutes) }\end{array}$ & $68.0 \pm 22.4$ & $89.0 \pm 17.3$ & 0.359 \\
\hline $\begin{array}{l}\text { Stones }>1000 \mathrm{HU} \\
\text { (minutes) }\end{array}$ & $99.5 \pm 36.0$ & $71.4 \pm 27.2$ & 0.288 \\
\hline $\begin{array}{l}\text { Stone area clearance } \\
\text { time }\left(\mathrm{mm}^{2} / \text { minute }\right)\end{array}$ & $4.7 \pm 1.8$ & $3.4 \pm 0.7$ & 0.218 \\
\hline $\begin{array}{l}\text { Stones }<1000 \mathrm{HU} \\
\left(\mathrm{mm}^{2} / \text { minute }\right)\end{array}$ & $8.9 \pm 1.0$ & $3.6 \pm 1.8$ & 0.019 \\
\hline $\begin{array}{l}\text { Stones }>1000 \mathrm{HU} \\
\left(\mathrm{mm}^{2} / \text { minute }\right)\end{array}$ & $3.7 \pm 1.6$ & $3.1 \pm 1.3$ & 0.786 \\
\hline $\begin{array}{l}\text { Stone volume clearance } \\
\text { time }\left(\mathrm{mm}^{3} / \mathrm{minute}\right)\end{array}$ & $70.4 \pm 35.1$ & $37.6 \pm 8.5$ & 0.312 \\
\hline $\begin{array}{l}\text { Conversion to } \\
\text { alternative technology }\end{array}$ & 3 & & 0.156 \\
\hline Complications & 1 & 1 & 0.945 \\
\hline $\begin{array}{l}\text { Device-related } \\
\text { complications } \\
\end{array}$ & 0 & 0 & 0.945 \\
\hline \multicolumn{4}{|l|}{ Postoperative } \\
\hline $\begin{array}{l}\text { Nil fragments of any } \\
\text { size }\end{array}$ & $54.50 \%$ & $62.50 \%$ & 0.257 \\
\hline
\end{tabular}

